\title{
EDITORIAL
}

\section{Remember elephants and icebergs... "Your lung function should be here, but it is there!"}

\author{
J.B. Soriano*,\# and G. Parkes
}

I $\mathrm{n}$ the present issue of the European Respiratory Journal, KOTZ et al. [1] report on a study aimed at determining the incremental benefit of spirometry in a smoking cessation intervention in individuals with as yet undiagnosed airflow obstruction compatible with mild and moderate chronic obstructive pulmonary disease (COPD). In a randomised clinical trial (RCT) study design, the authors compared an experimental group (nortriptyline and medium-intensity advice with spirometry) with two control groups: C1 (nortriptyline and mediumintensity advice without spirometry) and C2 (passive physician advice). The primary end-point was sustained cessation at week 52 with urinary cotinine-validated definitions. Regrettably, the study did not provide evidence that the confrontational approach increases the rate of long-term abstinence from smoking compared with an equally intensive treatment in which smokers were not confronted with spirometry.

In contrast, both the British Lung Age RCT by PARKES et al. [2] and the Swedish RCT by STRATELIS et al. [3], along with the large Polish cross-sectional study by BEDNAREK et al. [4], add support to the notion that giving information about lung damage to smokers improves cessation rates. Why do these results differ? There are many possible explanations. It is likely that a reduced sample size and the high failure rates $(>88 \%)$ in the trial by Kотz et al. [1] are at least partially to blame for the negative or inconclusive findings. KOTz et al. [1] had rather ambitious ideas about the degree of increased cessation rates that the lung damage challenge could produce (they powered their trial to detect a $35 \%$ cessation rate in the intervention group and a $20 \%$ rate in the control group), which are over and above the effects of the tricyclic antidepressant and motivational counselling. Unfortunately the study by KoTz et al. [1] failed to recruit or retain sufficient participants to gain statistical significance and, therefore, is vulnerable to a type-2 error, i.e. concluding that there is no difference when there is one. Furthermore, the participant population consisted of volunteers recruited by advertisements inviting people to attend a smoking cessation programme, as opposed to those being offered a lung health check. It is inevitable that different recruitment strategies

*Program of Epidemiology and Clinical Research, Fundación Caubet-CIMERA Illes Balears, Recinte Hospital Joan March, Bunyola, ${ }^{*}$ CIBER de enfermedades respiratorias, Spain, "The Limes Surgery, Hoddesdon, UK.

STATEMENT OF INTEREST: None declared.

CORRESPONDENCE: J.B. Soriano, Program of Epidemiology and Clinical Research, Fundación Caubet-CIMERA IIles Balears, Recinte Hospital Joan March, Carretera Soller Km 12, 07110 Bunyola, Spain. Fax: 34 971148442. E-mail: jbsoriano@caubet-cimera.es will attract different types of participants. Finally, KoTz et al. [1] used three interventions simultaneously, which may have the inadvertent effect of exhausting any independent effect of lung damage assessment and confrontation.

There is an urgent need to demonstrate efficacy and effectiveness of any smoking intervention strategies. The difficulty in proving convincingly that antismoking interventions work as we think they should highlight the need for treating tobacco addiction as a chronic relapsing disorder.

Tobacco consumption continues to be a huge threat to health. Quoting the European Lung White Book [5] when receiving the 2008 European Lung Foundation Award in Berlin, Germany last September [6], New York City Mayor Michael R. Bloomberg emphatically highlighted that $\sim 225$ million of the 750 million European citizens are smokers, and that, disappointingly, smoking prevalence is currently increasing in some European countries. Most smokers express a desire to quit, and surveys indicate that at least $60 \%$ have tried at least once. As a conservative estimate, tobacco kills over 650,000 people each year in the European Union [7].

It is estimated that $70-75 \%$ of the general population attends their primary care provider at least once per year; smokers more often than nonsmokers [7]. Therefore, the primary care setting should be a fundamental hub for any antismoking intervention [8-10]. On the one hand, efforts to establish primary care centres as hubs of spirometry for COPD screening and case finding have been accompanied with mixed results and confusing recommendations, and some authorities, including the US Preventive Services Task Force, do not recommend screening for early or asymptomatic COPD [11]. On the other hand, most clinicians at the primary [12] and specialised respiratory [13] level consistently agree that good quality spirometry should be implemented more extensively if we aim to achieve a real public health impact to reduce COPD burden. If the medical profession do not take the early signs of COPD seriously, it is likely that patients will also trivialise their condition. For those who are smoking or frequently relapse, this sends the wrong message, as we know that their disease will almost certainly progress with continued smoking. An important part of primary care concerns secondary prevention, i.e. early detection of disease and monitoring chronic illness. We already have a professional duty to diagnose early and monitor various conditions without actively treating them except with lifestyle advice (e.g. arterial hypertension, dyslipidaemia and hyperglycaemia). In the case of early COPD, once detected by screening, these individuals 
can be offered smoking cessation advice repeatedly and may benefit from other measures. Repeated testing should also allow earlier recognition of progression to a more serious level of disease requiring medication.

Even in the absence of the new evidence described in recent studies [1-4], it is well established that simple brief advice from a health professional increases the chances of smoking cessation [8]. Those with early lung damage are considered as the group at risk of accelerated deterioration of lung function compared with smokers who are not susceptible or nonsmokers [14]. It is not known if those with mild or asymptomatic COPD would benefit from other preventative care, such as pneumococcal or influenza vaccination. Meanwhile, the most important aim remains smoking cessation.

In contrast to KOTZ et al. [1], PARKES et al. [2] concluded that smoking cessation rates can be improved by reporting the individual's estimation of lung age with spirometry in primary care, and that screening smokers aged $>35$ yrs could reduce smoking and improve early diagnosis of COPD. Notably, in both trials, finding normal function did not appear to encourage continued smoking and may, in fact, encourage people that it is not too late to quit.

Undiagnosed chronic obstructive pulmonary disease patients have been called the "missing millions" [15]. This is like the proverbial "elephant in the room", which everyone tries to ignore because they feel powerless to face the problem. In Europe, we can either follow by ignoring the elephant [16], and the coming iceberg producing maximum destruction [17], or we can take on the challenge of confronting the problem. Further research will eventually determine whether this is worthwhile or misguided, but can we afford to wait another five or ten years for more proof to help us decide?

\section{REFERENCES}

1 Kotz D, Wesseling G, Huibers MJH, van Schayck OCP. Efficacy of confronting smokers with airflow limitation for smoking cessation. Eur Respir J 2009; 33: 754-762.

2 Parkes G, Greenhalgh T, Griffin M, Dent R. Effect on smoking quit rate of telling patients their lung age: the Step2quit randomised controlled trial. BMJ 2008; 336: 598-600.

3 Stratelis G, Mölstad S, Jakobsson P, Zetterström O. The impact of repeated spirometry and smoking cessation advice on smokers with mild COPD. Scand J Primary Health Care 2006; 24, 3: 133-139.

4 Bednarek M, Gorecka D, Wielgomas J, CzajkowskaMalinowska M, Regula J, Mieszko-Filipczyk G. Smokers with airway obstruction are more likely to quit smoking. Thorax 2006; 61: 869-873.

5 European Respiratory Society/European Lung Foundation. The European Lung White Book: The First Comprehensive Survey on Respiratory Health in Europe. Loddenkemper R, Gibson GJ, Sibille Y, eds. Sheffield, ERSJ, 2003.

6 Bloomberg MR. 'The responsibility for leadership falls most heavily on those with the means to exercise it'. Breathe 2008; 5: 116-119.

7 The ASPECT Consortium. Tobacco or Health in the European Union: Past, present and future. Brussels, European Bureau for Action on Smoking Prevention, Tobacco and Health in the European Union, 2004.

8 Stead LF, Bergson G, Lancaster T. Physician advice for smoking cessation. Cochrane Database Syst Rev 2008; 2: CD000165.

92008 PHS Guideline Update Panel, Liaisons, and Staff. Treating tobacco use and dependence: 2008 update U.S. Public Health Service Clinical Practice Guideline executive summary. Respir Care 2008; 53: 1217-1222.

10 Smith-Sivertsen T, Rortveit G. Should general practitioners screen smokers for COPD? Scand J Prim Health Care 2004; 22: 196-201.

11 Lin K, Watkins B, Johnson T, Rodriguez JA, Barton MB, Preventive Services Task Force US. Screening for chronic obstructive pulmonary disease using spirometry: summary of the evidence for the U.S. Preventive Services Task Force. Ann Intern Med 2008; 148: 535-543.

12 Tinkelman DG, Price D, Nordyke RJ, Halbert RJ. COPD screening efforts in primary care: what is the yield? Prim Care Respir J 2007; 16: 41-48.

13 Derom E, van Weel C, Liistro G, et al. Primary care spirometry. Eur Respir J 2008; 31: 197-203.

14 Fletcher C, Peto R. The natural history of chronic airflow obstruction. BMJ 1977; 1: 1645-1648.

15 British Lung Foundation. Brown's screening programme overlooks UK's second biggest killer. www.lunguk.org/mediaand-campaigning/media-centre/archive-press-releases-andstatements/jan2008/

BrownsscreeningprogrammeoverlooksUKssecondbiggestkiller.htm Date last accessed: October 11, 2008. Date last updated: January 7, 2008.

16 Mannino DM. Defining chronic obstructive pulmonary disease... and the elephant in the room. Eur Respir J 2007; 30: 189-190.

17 Goldacre MJ. Cause-specific mortality: understanding uncertain tips of the disease iceberg. J Epidemiol Community Health 1993; 47: 491-496. 